\title{
FERRAMENTA DE DIAGNÓSTICO DE USO DO WHATSAPP EM AMBIENTE ORGANIZACIONAL
}

\author{
DIAGNOSTIC TOOL FOR USE IN ORGANIZATIONAL ENVIRONMENT
}

HERRAMIENTA DE DIAGNÓSTICO PARA EL USO DE WHATSAPP EN EL ENTORNO ORGANIZACIONAL

\section{Márcio Carneiro dos Santos}

Professor Permanente do Programa de Mestrado Profissional em Comunicação

Doutor em Tecnologias da Inteligência e Design Digital pela PUC-SP

Professor Adjunto IV

marcio.carneiro@ufma.br

0000-0002-0183-8417

\section{Miguel Dias Abdalla}

Graduado em Comunicação Social com habilitação em Relações Públicas e Mestrando em Comunicação miguel@ideiapropaganda.com

0000-0001-5235-6402

\section{Protásio Cézar dos Santos}

Professor Permanente do Programa de Mestrado Profissional em Comunicação

Doutor em Ciências Ambientais

Professor Associado IV

pcsftslz@gmail.com

\section{0-0003-0250-124X}

Correspondência: Universidade Federal do Tocantins, Reitoria, DIRETORIA DE COMUNICAÇÃO. Quadra 109 Norte Avenida NS 15, Plano Diretor Norte, 77001090 Palmas, TO - Brasil.

Recebido em: 16.02.2021.

Aceito em: 16.04 .2021

Publicado em: 01.07.2021.

\section{RESUMO:}

Apresenta-se um recorte de trabalho em andamento, cujo objetivo é desenvolver uma ferramenta de diagnóstico da utilização do WhatsApp em ambientes organizacionais. O projeto, orientado para o enfrentamento de situações reais, caracteriza a iniciativa como pesquisa aplicada. A solução envolve um instrumento de coleta de dados, uma categorização das formas de uso e um algoritmo para análise exploratória básica das conversas nos grupos, identificados entre os colaboradores. Partindo de um referencial teórico que aponta para as mudanças decorrentes da digitalização dos processos sociais de circulação de informação, a aplicação teste está ocorrendo no SEBRAE-MA, tendo demonstrado efetividade na identificação de problemas específicos, permitindo, assim, a proposição de iniciativas de mitigação e melhor utilização.

PALAVRAS-CHAVES:

Organizacional.

Comunicação Contemporaneidade. ecnologias digitais de Informação e Comunicação.

\section{Introdução}

O universo corporativo vem passando por profundas transformações. Novos conceitos, formas de gestão e tecnologias determinam outras configurações às empresas, alteram a estrutura dos mercados, o comportamento dos consumidores e as relações entre o capital e o trabalho, causando impactos na vida social, nos valores, na política e na cultura.

Nesse cenário, a comunicação organizacional passou a ser ferramenta estratégica essencial para estabelecer o diálogo entre a empresa e seus diversos públicos. Está ligada ao compartilhamento de sentimentos, informações, conhecimentos e interesses e se apresenta como um fenômeno que reúne complexidade e convergência.

Entender a comunicação como fator essencial para a existência das organizações, na contemporaneidade, está se tornando cada vez mais necessário. 
No contexto da sociedade digitalizada, o cenário para as organizações é bastante complexo e necessita de uma sucessão de mudanças, ajustes e restruturações, que envolvem toda a organização em seus diferentes aspectos.

De acordo com Corrêa (2016, p. 60):

[...] o protagonismo da atividade comunicativa nas organizações tem se evidenciado proporcionalmente à intensidade da consolidação das Tecnologias Digitais de Informação e Comunicação (TICs) na sociedade contemporânea.

A adoção de ferramentas digitais por parte dos agentes que pertencem à organização causa impactos internos e externos.

Entender as repercussões que tais mudanças geram é fator fundamental para continuar mapeando a evolução dos ecossistemas comunicacionais nesses ambientes. "As realidades mutantes, cada vez mais presentes no mundo das organizações e dos sujeitos organizacionais, por sua vez, implicam necessariamente um (re) visitar permanente das concepções de comunicação, organização e sujeito organizacional" (SCROFERNEKER, 2008, p.7).

Essa lógica da autora confere à comunicação organizacional, um importante e fundamental valor às organizações. No que tange a comunicação interna, as inovações permeiam seus canais, instrumentos, práticas e até políticas com o público interno. Sobre a comunicação interna, Marchiori (2008, p. 21-216) afirma que:

\begin{abstract}
A comunicação interna planejada e avaliada é uma ferramenta estratégica que estimula o diálogo entre lideranças e funcionários. Oportuniza a troca de informações via comunicação, contribuindo para construção do conhecimento, o qual é expresso nas atitudes das pessoas. É fundamental um processo que engloba a comunicação administrativa, fluxos, barreiras, veículos, redes formais e informais. Promove, portanto, a interação social e fomenta a credibilidade, agindo no sentido de manter viva a identidade de uma organização.
\end{abstract}

Um exemplo de ferramenta para a comunicação interna é o aplicativo de mensagens WhatsApp, que por sua popularidade nos âmbitos pessoal e organizacional, possibilita as mais variadas interações. Tem a opção de criar grupos para estender a comunicação com mais pessoas e assume a liderança do ranking de aplicativos mais usados no mundo, em sistemas IOS e Android. Tornou-se também, de acordo com o relatório mais recente da empresa de análise App Annie, o aplicativo que teve mais usuários ativos, e, no Brasil, o aplicativo mais popular (ALVES, 2019).

É necessário planejar novos caminhos que possibilitem uma ressignificação da comunicação interna das organizações, com maior alcance, considerando a pluralidade, 
agilidade, familiaridade e possibilidade inicial de interação, que, até então, era apenas informativa, de mão única, por meio de jornal mural, house-organs e comunicados.

Como entender e implementar de forma mais efetiva as inovações tecnológicas aos processos de comunicação organizacional? No caso específico do WhatsApp, como está sendo adotado? Como ferramenta corporativa, pessoal ou híbrida? Tais formas exigem controle? Como essa utilização pode ajudar ou atrapalhar a organização? Essas parecem ser questões relevantes e traduzem um dos maiores desafios que as organizações precisam enfrentar nos dias de hoje: saber estruturar seu modelo de gestão da comunicação com os empregados, onde a tradição e a inovação coexistam, se necessário.

\section{Novas ferramentas para investigar a mudança}

A prática da comunicação interna nas organizações precisa saber compatibilizar inovação tecnológica, mudanças comportamentais, novos contextos sociais, novas demandas de mercado, a manutenção e o aprimoramento de meios tradicionais, que ainda funcionam e são relevantes para muitas empresas e instituições.

Para incorporar todo o aparato tecnológico das mídias digitais, essa área precisa se posicionar de forma estratégica, colaborando no processo de competências digitais e nas mudanças da cultura organizacional. Os canais de comunicação com o público interno devem ser complementares, ou seja, todos podem veicular as mesmas informações, porém, considerando seus atributos e peculiaridades, como formatos, conteúdos, distribuição e periodicidade.

Entretanto, somente com estratégias envolvendo meios digitais, ilimitados em suas operações, é que os empregados terão oportunidade de colaborar e se engajar nos processos comunicacionais da empresa em que trabalham.

Callon (2010) defende a profunda compatibilidade entre a inovação e a tradição. O autor articula suas ideias a respeito de aspectos técnico-econômicos e sociológicos da inovação e, na sua abordagem, destaca que a inovação é um processo coletivo, fruto de uma rede formada por elementos humanos e não humanos. A inovação deve se nutrir e se enriquecer com a tradição e não a destruir. "Ninguém conhece o fim da viagem. Não sabemos aonde vamos, mas vamos juntos: esta é a beleza da inovação" (CALLON, 2010, p. 72).

Segundo Kunsch (2016, p. 149):

A comunicação organizacional é a disciplina que estuda como se processa o fenômeno comunicacional dentro das organizações no âmbito da sociedade global. Ela analisa o sistema, o funcionamento e o processo de comunicação entre a organização seus diversos públicos. 
Diante disso, deve-se considerar que novas formas de comunicação interna nas organizações são resultadas de um esforço coletivo, feito de vontades e interesses individuais de líderes e empregados, que negociam e, gradualmente, constroem e legitimam soluções e instrumentos em uma ação conjunta. Na contemporaneidade, mais do que nunca, os empregados têm acesso a uma extensa rede de informação e a sofisticados canais de expressão e comunicação, ofertados pelas redes sociais. As relações no ambiente interno das organizações são baseadas em processos midiatizados, com novos espaços de trocas simbólicas e mais horizontalizadas.

O WhatsApp foi lançado em 2009, nos Estados Unidos, por Jan Koum e Brian Acton, ambos ex-funcionários da empresa Yahoo!, que, incomodados com a proibição do uso de celulares na universidade em que estudavam, criaram uma solução para as ligações perdidas. O nome deriva da expressão em inglês What's up? que significa, em tradução livre, "E aí?" ou "Tudo bem?". Ele incorpora, ainda, diversos recursos, como o envio e o recebimento de figuras ou imagens animadas, emoticons (comunicação paralinguística) e emojis, arquivos em formato portátil de documento, endereços de páginas da Internet, áudios, vídeos e figuras (HELENA, 2013).

No ambiente das organizações, o aplicativo mostrou-se útil por potencializar procedimentos e diminuir custos, avizinhando consumidores e empresas, aumentando as chances de negócios e vendas, fornecendo respostas imediatas às necessidades das pessoas e intensificando e aproximando as distâncias de mercado.

Com mais de 2 bilhões de usuários no mundo inteiro e disponível em mais de 180 países, o WhatsApp é, sem dúvida, o aplicativo mais popular do planeta. Desse total de usuários ativos, estima-se que mais de 120 milhões estão no Brasil. Segundo pesquisa realizada pelo Senado Federal, no final de 2019, 79 \% dos brasileiros usam o aplicativo como principal fonte de informação. Em segundo e terceiro lugares, respectivamente, aparecem os canais tradicionais de informação e as redes sociais (BRASIL 2019).

Lançada em janeiro de 2018, a versão WhatsApp para empresas surgiu como iniciativa para entrar no mercado de comunicação empresarial, permitindo que usuários melhorem a forma de interagir com clientes, através de ferramentas de automação e classificação de imagens.

Conforme dados coletados pelo Serviço Brasileiro de Apoio às Micro e Pequenas Empresas, (SEBRAE) com apenas um ano de existência, o WhatsApp Business já alcançou a marca de 5 milhões de usuários e é utilizado por $72 \%$ dos empreendedores brasileiros (SEBRAE, 2019). Gabriel (2010, p. 73) destaca que: 
[...] é inegável que as tecnologias digitais têm se tornado cada vez mais presentes em todos os aspectos da vida humana - social, profissional, pessoal -, impactando e afetando a sociedade, a cultura, o modo como vivemos e interagimos com o mundo.

Brum (2017) afirma que o WhatsApp passou a ser usado como canal de comunicação com o público interno, em dois modelos: o tradicional e o central de conectividade. O primeiro é o modelo pelo qual o líder se comunica com sua equipe e o segundo modelo, por meio de uma central de conectividade, para que a empresa se comunique com todo o seu público interno ou grupos de empregados.

Com relação ao aplicativo interno e ao WhatsApp, é importante considerar que as vidas pessoal e profissional estarão cada vez mais unidas e os smartphones se tornaram mais utilizados para comunicação com o público interno. Obviamente, a tendência das empresas é continuar evoluindo em relação às tecnologias oferecidas pelo mercado.

Embora saibamos que é um caminho sem volta, tudo depende do quanto as empresas estão abertas para disponibilizar e compartilhar conteúdos importantes e estratégicos, pois, assim como a tecnologia facilita o processo da informação, também provoca a exposição do seu emissor (BRUM, 2017, p. 121).

Um aspecto essencial no uso dessa ferramenta inovadora, somados à tecnologia, é a utilização de metodologia, planejamento e estratégia muito bem definidos. Desse modo, os empregados terão os canais com diálogos mais rápidos, como fontes seguras e oficiais, criando um vínculo de confiança com a organização. O espaço gerado para a troca de informações, experiências e conteúdos é, certamente, um dos maiores benefícios das redes sociais internas.

Se alguns aspectos da questão são mais claros, outros precisam ser investigados. As organizações não são iguais e a utilização do WhatsApp - WA, também se apresenta com diversas variações em escala, forma de utilização e impactos. Assim, para iniciar qualquer tipo de planejamento estratégico ligado a gerar melhor efetividade no uso do WA, é necessário primeiro um diagnóstico que possa identificar as peculiaridades da adoção e identificar potenciais problemas na mesma, a fim de, então, propor medidas mais orientadas a um uso mais efetivo e sinérgico.

\section{Ferramenta de diagnóstico de utilização do WA em organizações}


A ferramenta de diagnóstico ora apresentada constitui-se de um processo detalhado a seguir:

Aplicação de instrumento de coleta de dados junto aos colaboradores sobre a atual situação de uso do WA na organização. Para tanto, foi elaborado um formulário online, capaz de ser aplicado, inclusive, remotamente e que pode ter como público, apenas setores específicos da organização (setor de Comunicação, por exemplo) ou até, todo o conjunto de pessoas envolvidas com a organização.

1. Análise dos dados inicialmente coletados na etapa anterior para caracterização de uma matriz de uso a ser explicada abaixo.

2. Opcionalmente, realizar grupo focal para explorar com mais detalhes questões suscitadas pelos dados do formulário inicial.

3. Aplicação da matriz de uso de forma a gerar um perfil de utilização estruturado e, por isso, possibilitando posteriores transformações, inclusive automatizadas, via algoritmos.

4. Opcionalmente, aplicar código para análise exploratória básica de conversação nos grupos de WA que possam gerar insights sobre atores, relevância e modos de utilização. Esse código foi desenvolvido por um dos autores, o professor Márcio Carneiro dos Santos e será disponibilizado em breve, através do site do LABCOM (www.labcomdigital.com.br).

5. Análise geral dos dados levantados seguida de geração de relatório, caracterizando a utilização, os principais problemas identificados e eventuais ações para corrigir ou aumentar a performance da utilização.

\section{Metodologia}

Para este estudo exploratório foi escolhida uma organização local, no caso, o SEBRAE-MA, que, a partir de contatos iniciais, mostrou-se interessada em participar da pesquisa.

Trata-se de um processo ainda em andamento (work in progress) no qual já foi aplicado um formulário inicial apenas no grupo ligado à Comunicação do órgão. Tal procedimento foi efetivado como um teste para qualificar o próprio conjunto de questões e será agora ampliado para todo o corpo de colaboradores.

As outras instâncias do processo, no caso, a matriz de utilização e o algoritmo para análise básica da conversação nos grupos, já foram desenvolvidos.

O SEBRAE é uma entidade privada, sem fins lucrativos, que promove a competitividade e o desenvolvimento sustentável dos micros e pequenos empreendimentos - aqueles com faturamento bruto anual de até 4,8 milhões. 
A instituição atua com foco no fortalecimento do empreendedorismo e na aceleração do processo de formalização da economia, por meio de parcerias com os setores público e privado, programas de capacitação, orientação para o acesso ao crédito e à inovação, estímulo ao associativismo e cooperativismo, promoção de feiras, rodadas de negócios e outras ações de acesso e ampliação de mercado para Micro e Pequenas Empresas (MPE) além do fomento, junto a governos federal, estaduais e municipais, para melhoria no ambiente legal para os pequenos negócios locais, por meio da desburocratização e da inclusão desses empreendimentos nas compras públicas.

No Maranhão, o público interno do SEBRAE é formado por colaboradores/empregados, trainees, estagiários, menores aprendizes, terceirizados, dirigentes e conselheiros, num total de 275 pessoas.

Para a análise, observação e levantamento de informações para esta pesquisa, o universo escolhido será o SEBRAE-MA e as onze Unidades Regionais de Negócios situadas em São Luís, Pinheiro, Lençóis Munim, Santa Inês, Bacabal, Chapadinha, Caxias, Presidente Dutra, Balsas, Açailândia e Imperatriz.

O questionário, disponibilizado no Google Forms em outubro de 2020, foi elaborado com base em tópicos sobre o objeto de estudo, o uso WA na instituição e as melhores práticas na utilização desse aplicativo. Com um total de 109 respostas para 30 questões, sendo 27 com perguntas fechadas e 3 com perguntas abertas. Todos os funcionários da Gerência colaboraram e responderam à pesquisa, anonimamente e de forma autônoma.

Para elaboração do questionário, os seguintes tópicos foram elencados:

-De que forma o aplicativo WA está sendo utilizado pelos dirigentes e funcionários da instituição;

-De que maneira o aplicativo WA está inserido nos processos comunicacionais internos da instituição;

-Se o aplicativo WA é incluído frequentemente no planejamento das campanhas internas da instituição;

-Quantos grupos de WA existem atualmente na instituição;

-Quem administra os grupos de WA da instituição;

-Quais as vantagens percebidas no uso do aplicativo WA pela instituição;

-Quais os tipos de mensagem são utilizados nos grupos do aplicativo WA da instituição;

-Qual é o fluxo de comunicação em que o aplicativo é mais utilizado na instituiç̧ão; 
-Qual é o nível de comunicação em que o aplicativo é mais utilizado na instituição;

-Quais são as melhores práticas no uso do aplicativo WA na instituição

-Existe algum protocolo de uso do aplicativo WA na instituição;

-O uso do aplicativo WA foi intensificado, em função da pandemia;

-A instituição está adotando a versão business do aplicativo;

-Se todos os funcionários possuem aparelho celular corporativo e plano de telefonia móvel;

- Qual é o nível de engajamento da equipe no aplicativo WA da instituição.

Como resultado dessa fase, a partir de ajustes, criou-se um instrumento que passou por um pré-teste e também pode ser utilizado com a mesma estrutura nas próximas etapas da pesquisa, que compreendem coletar dados dos demais públicos considerados internos no SEBRAE - MA, bem como para entidades que apresentem o mesmo perfil da instituição.

O universo a ser pesquisado é formado pelos seguintes quantitativos: 159 colaboradores/empregados, 42 estagiários, 8 menores aprendizes, 27 terceirizados, 3 dirigentes e 36 conselheiros.

\section{Matriz de utilização}

A matriz de utilização desenvolvida prevê as seguintes variáveis ou métricas para análise:

a) Dispersão - índice de utilização em caráter individual - quanto maior a dispersão menos uso corporativo ou formal foi identificado;

b) Tamanho - está relacionado à quantidade de utilizadores identificados;

c) Diversidade/Homogeneidade - nesse aspecto são analisados os grupos ou clusters de utilizadores, agrupados por segmentos de gênero, hierarquia e outros;

e) Direção do Fluxo - observa o sentido das mensagens numa perspectiva hierárquica e vertical;

f) Nível de Formalidade - avalia o grau de institucionalidade do grupo a partir dos textos publicados;

g) Horários - verifica a utilização dentro e fora do período formal de trabalho;

h) Multimidialidade - observa a utilização de imagens, vídeo e áudios dentro do total da utilização.

i) Identidade visual - observa a utilização de elementos visuais ligados à organização. 
Em síntese, analisando os dados obtidos com base na Matriz de Utilização, pode-se visualizar, através de um quadro (Figura 1), as variáveis ou métricas numa escala de 1 a 5, onde 1 corresponde a um grau mais elevado e o 5, um grau mais baixo.

Figura 1 - Quadro Matriz de Utilização

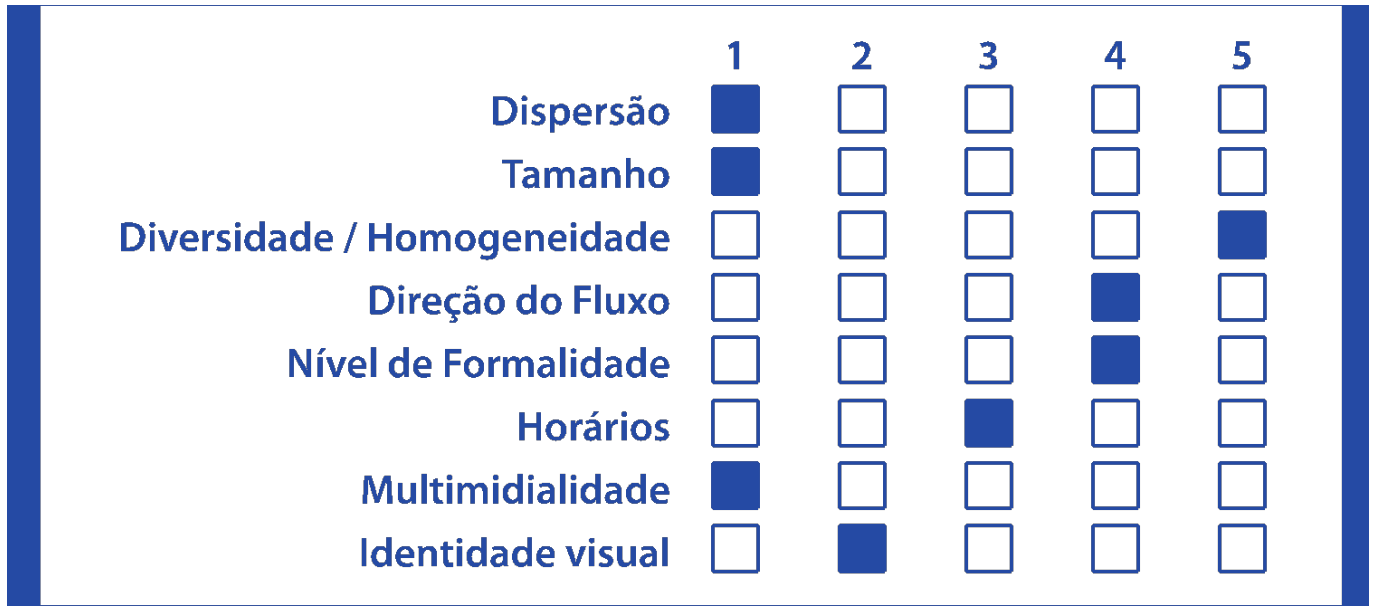

Fonte: Autores (2021)

\section{Algoritmo para análise de grupos}

Desenvolvido pelo professor Márcio Carneiro, coordenador do LABCOM/UFMA, o LWA (LABCOM WHATSAPP) é uma ferramenta que a partir dos arquivos de conversação de grupos, que podem ser exportados por meio do próprio aplicativo, permite análises exploratórias simples como verificação de centralidade entre os membros do grupo, identificação de perfil, nível de utilização de emoticons, caracterização de períodos mais frequentes de utilização entre outras métricas. O software estará disponível para pesquisadores cadastrados no segundo semestre de 2021 em modo de teste e terá seu acesso via web a partir da solução Google Colab. Abaixo seguem algumas imagens das telas geradas pelo LWA. Na figura 2 temos um print do dataset gerado que organiza data e hora de publicação, autores, mensagens e contagens diversas.

Figura 2 - Dataset extraído do arquivo de conversas 


\begin{tabular}{|c|c|c|c|c|c|c|c|c|}
\hline & Date & Time & Author & Message & emoji & urlcount & Letter_Count & Word_Count \\
\hline 1 & $10 / 06 / 2019$ & $12: 56$ & & Com muita satisfação e alegria publicamos o li... & [] & 1 & 377 & 57 \\
\hline 2 & $10 / 06 / 2019$ & $12: 57$ & & 10 & [b] & 0 & 39 & 6 \\
\hline 3 & $10 / 06 / 2019$ & $12: 58$ & & 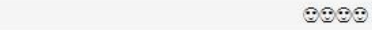 & {$[\Theta, \Theta, \Theta, \Theta]$} & 0 & 4 & 1 \\
\hline 4 & $10 / 06 / 2019$ & $12: 59$ & & $\operatorname{cosec}=$ & {$[\because=,-z, \Sigma=]$} & 0 & 6 & 1 \\
\hline 5 & $10 / 06 / 2019$ & 13:01 & & $\operatorname{cosececectu}$ & 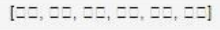 & 0 & 12 & 1 \\
\hline$\cdots$ & & $\ldots$ & & $\ldots$ & $\ldots$ & & $\ldots$ & $\ldots$ \\
\hline 4913 & 08/07/2020 & $17: 28$ & & Repassa & [] & 0 & 7 & 1 \\
\hline 4914 & $08 / 07 / 2020$ & $17: 32$ & & $=\overline{-}$ & {$[=z]$} & 0 & 2 & 1 \\
\hline 4915 & $08 / 07 / 2020$ & $17: 32$ & & grata & [] & 0 & 5 & 1 \\
\hline 4918 & $08 / 07 / 2020$ & $20: 25$ & & Perfeitol Depois vamos organizar a proposta da... & [0] & 0 & 88 & 14 \\
\hline 4919 & 08/07/2020 & $20: 27$ & & Tá certo & [] & 0 & 8 & 2 \\
\hline
\end{tabular}

Fonte: LABCOM - UFMA (2021)

Figura 3 - Exemplos de relatórios possíveis para extração

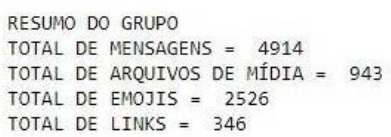

Stats of Marcio Carneiro dos Santo Messages Sent 329

(10

Media Messages Sent 94

Emojis Sent 179

Links Sent 41

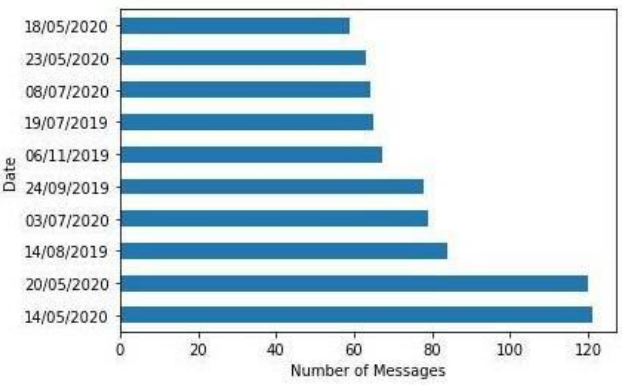

Fonte: LABCOM - UFMA (2021)

$\mathrm{Na}$ figura 3, demonstram-se alguns conjuntos de métricas que podem ser extraídos, tais como números gerais de publicação do grupo, números individuais dos participantes, tais como o número de mensagens enviadas e média de palavras por mensagem, bem como contagem e classificação de emojis e datas com maior quantidade de mensagens.

Abaixo na figura 4, temos uma nuvem de palavras mais frequentes, gerada pelo próprio software, a partir da conversa do grupo.

Figura 3 - Nuvem de palavras mais frequentes na conversação do grupo 


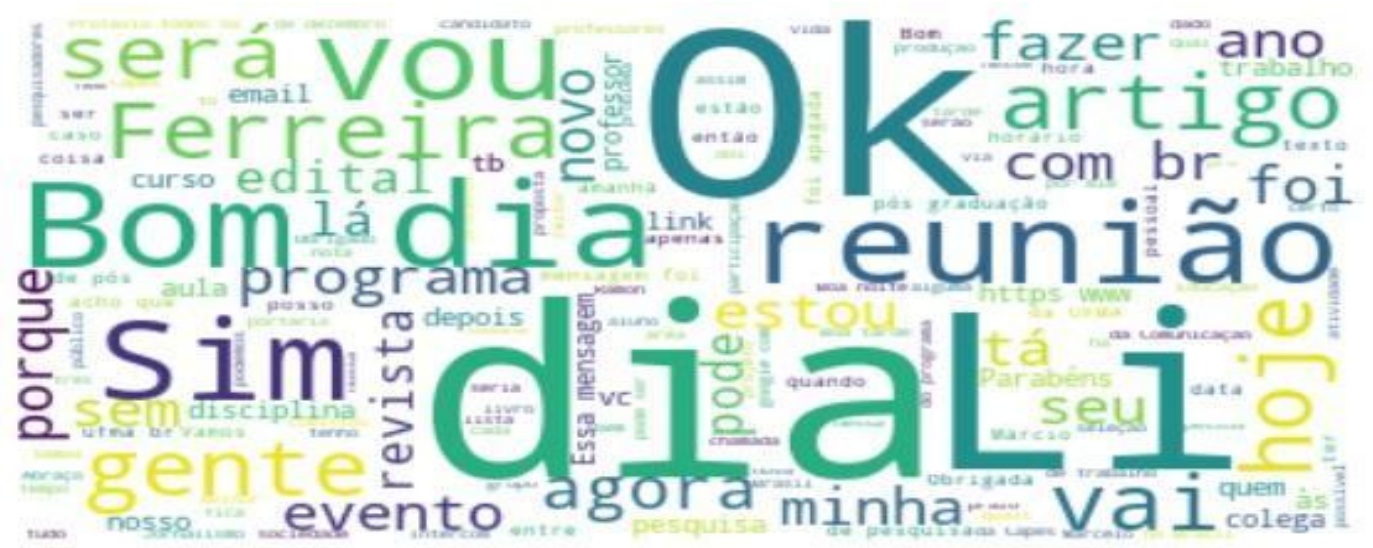

Fonte: LABCOM - UFMA (2021)

\section{Análise preliminar}

Como exemplo de sistematização na interpretação dos dados, apresentam-se alguns indicadores para o aprofundamento da análise, obtidos na pesquisa realizada com a equipe da Gerência de Comunicação e Marketing do Sebrae- MA. A categoria proposta é a existência de um protocolo no uso do aplicativo WhatsApp.

Gráfico 1 - Existe algum protocolo de uso do aplicativo WhatsApp na instituição?

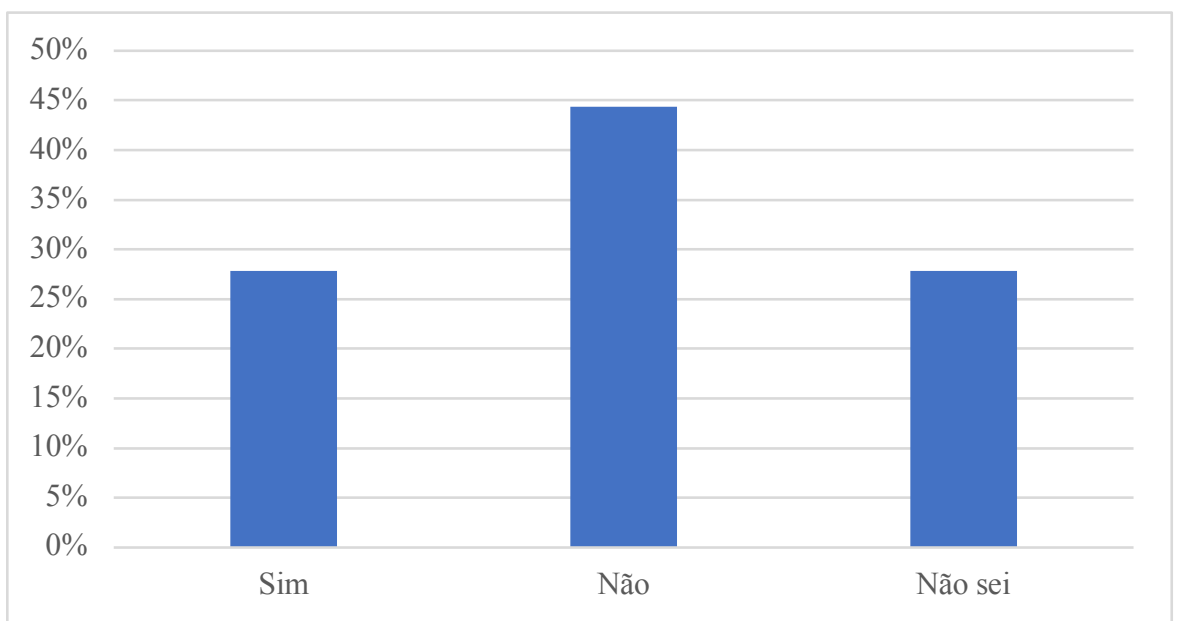

Fonte: Autores (2021)

A Gerência de Comunicação e Marketing do SEBRAE- MA opinou sobre a existência de um protocolo no uso do aplicativo WhatsApp na instituição, sendo, 44,5\% dos respondentes entendem que não existe tal protocolo, $27,8 \%$ avaliam que existe e $27 \%$ responderam que não sabem. Os dados aqui apresentados apresentam indícios de 
haver um protocolo de utilização do WhatsApp, na comunicação interna da instituição, o que parece não representar a realidade.

Gráfico 2 - A utilização se dá apenas em horário de trabalho?

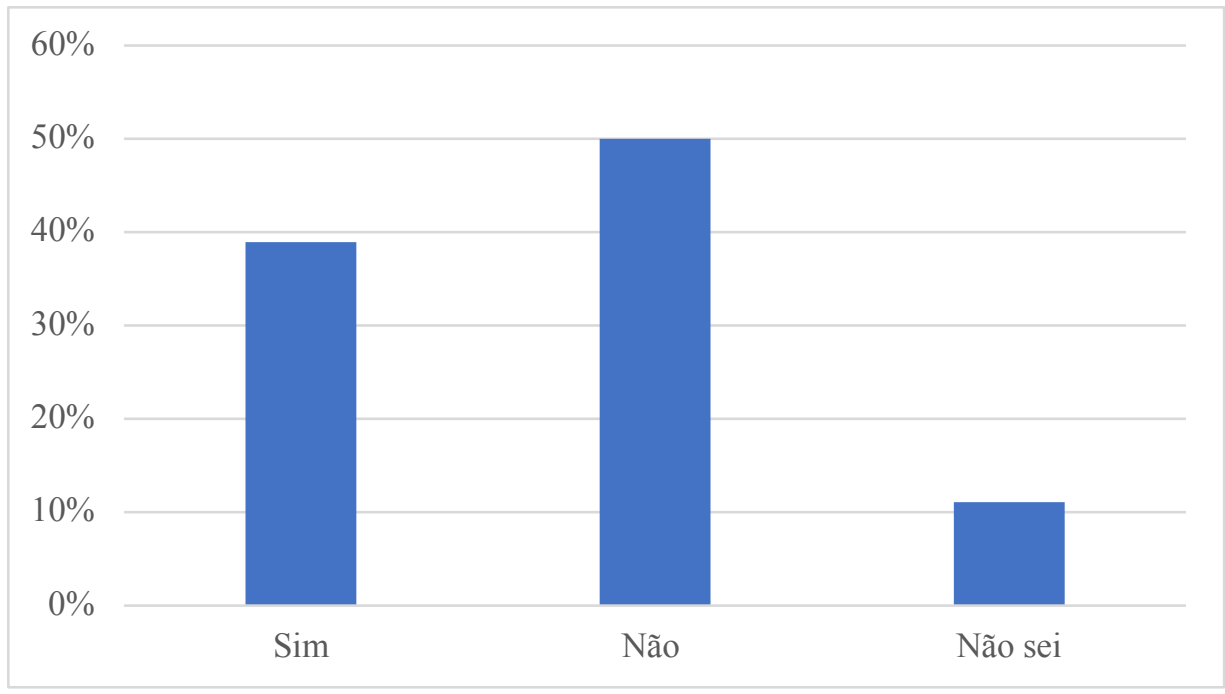

Fonte: Autores (2021)

A questão representada no gráfico 2 pretendia investigar se o Grupo de WhatsApp da Gerência de Comunicação era utilizado somente nos dias e horários de trabalho. 50\% dos respondentes apontaram que não, 38,9\% responderam que sim e $11 \%$ disseram não saber. Percebe-se que a maioria dos integrantes dessa equipe afirmam que o uso do aplicativo WhatsApp pela Gerência está sendo feito fora do horário normal, podendo ser caracterizado como hora extra da jornada de trabalho.

Gráfico 3 - Na sua opinião, de que forma o aplicativo WhatsApp está sendo utilizado pelos dirigentes, funcionários e colaboradores da instituição? 


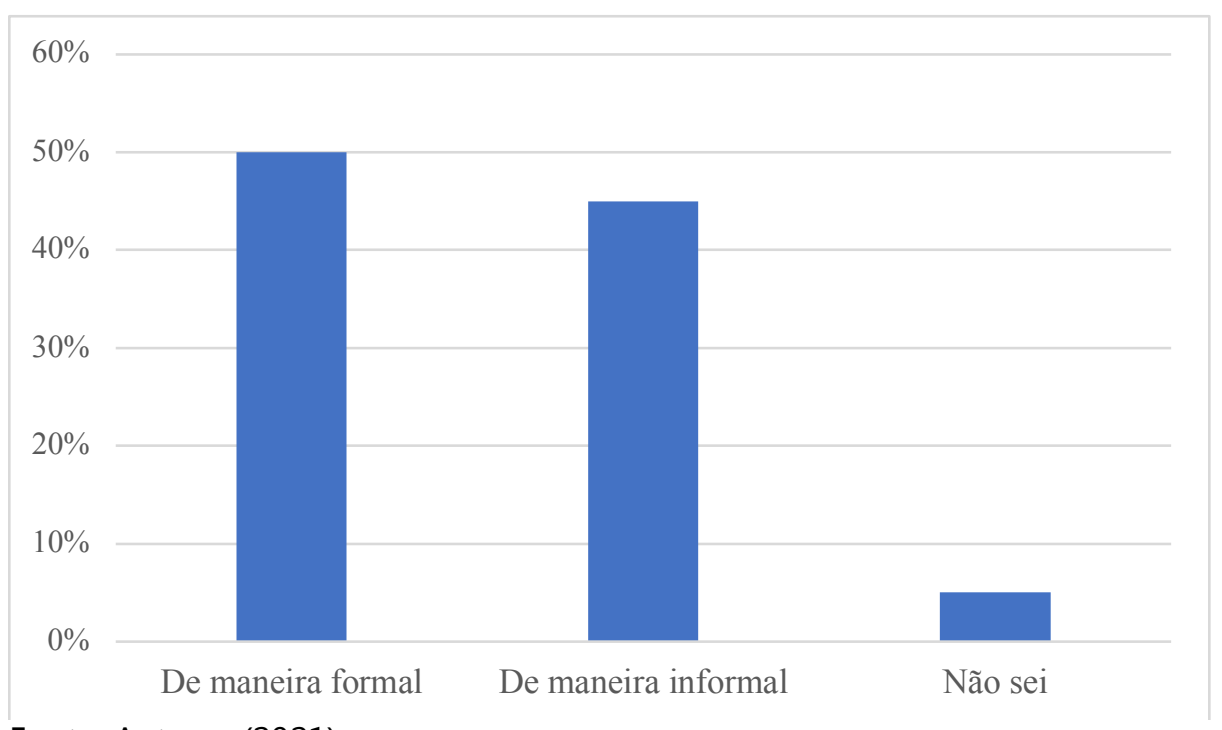

Fonte: Autores (2021)

Identificar a percepção do uso do aplicativo como sendo um instrumento de comunicação contratado e requerido pela instituição também foi objeto da pesquisa de campo. 50\% responderam que o uso é de maneira informal, 44,4\% avaliam que é de maneira formal e o 5,6 \% apontaram que não sabem. A maioria dos respondentes apontou que o aplicativo de mensagem não faz parte da estrutura comunicacional da instituição.

Segundo Kunsch (2016, p. 82), as comunicações formal e informal convivem simultaneamente nas organizações: "[...] o sistema formal de comunicação de toda organização - o conjunto de canais e meios de comunicação estabelecidos de forma consciente e deliberada". Quanto ao sistema informal de comunicações, ele emerge das relações sociais entre as pessoas.

$\mathrm{Na}$ interpretação desses dados da pesquisa de campo realizada, percebeu-se não existir dentre os funcionários da Gerência de Comunicação e Marketing do SEBRAE- MA um consenso, nem tão pouco um alinhamento a respeito do uso aplicativo como instrumento de comunicação interna. Talvez isso deva -se ao fato que, no departamento, 14 pessoas são terceirizadas e somente 4 são funcionários, que vivenciam mais a organização no seu dia a dia. A partir dessas interpretações, a princípio, pode-se, ao finalizar todos os ciclos de pesquisa, entrevistas e grupos focais com os demais públicos internos da instituição, incluir também na proposição de implementação de melhores práticas estratégias e ações específicas para os terceirizados da instituição.

Outro ponto de análise diz respeito à questão aberta - Quais as suas sugestões para a melhoria na utilização do aplicativo WA na sua organização? A nuvem de palavras abaixo (Figura 4) ilustra as respostas obtidas, possibilitando uma visão geral das opiniões dos respondentes: 
Figura 4 - Nuvem de palavras da trigésima questão

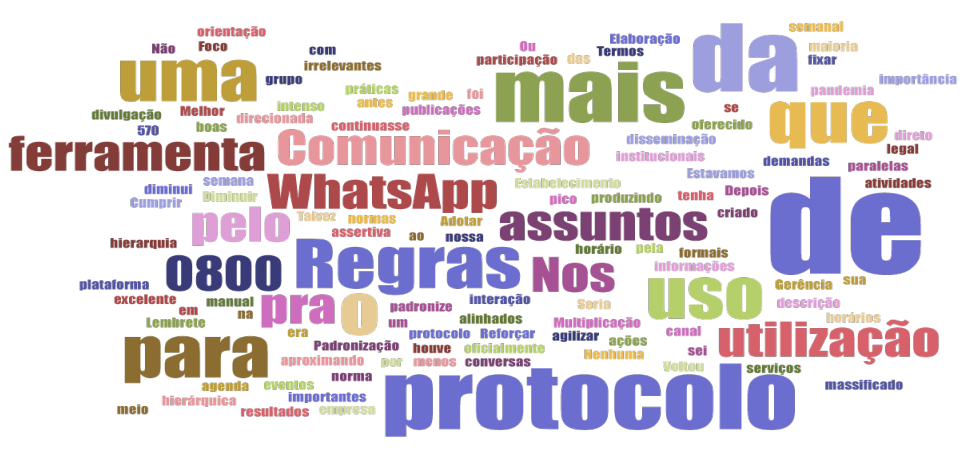

Fonte: Autores (2021)

\section{Considerações finais}

Apesar de tratar-se de um trabalho ainda em andamento, o desenvolvimento deste produto, no caso, a ferramenta de diagnóstico para avaliação do uso do WA em organizações, tem se mostrado como promissor, diante da constatação de poucas opções semelhantes para solucionar a questão fundamental de entender a adoção de ferramentas tecnológicas no ambiente organizacional.

A partir de uma metodologia que sugere abordagem qualitativa e quantitativa, a solução se insere no que se espera de uma iniciativa de pesquisa aplicada que pretende enfrentar problemas reais e oferecer melhorias em cenários já existentes.

O potencial de utilização da ferramenta vai além do caso do SEBRAE-MA, utilizado como piloto para o seu desenvolvimento. Todo o processo permite fácil adaptação para outras organizações, sejam elas públicas, privadas ou do terceiro setor.

O espectro de utilizadores potenciais também vai além de gestores dessas organizações, mas também, estende-se a pesquisadores e profissionais da Comunicação interessados em analisar ou efetivamente diagnosticar ambientes corporativos, onde o WA é uma das ferramentas tecnológicas utilizadas em âmbito interno.

Os elementos dessa metodologia de diagnóstico podem ser também adaptados e utilizados conforme a necessidade, com as opções de elementos mais conceituais, como a matriz de utilização, bem como mais pragmáticas, como o código do LWA, que permite análise exploratória inicial sobre a conversação dos grupos.

A capacidade de identificar questões importantes a serem atacadas, por um posterior planejamento estratégico específico para o tema demostra que a ferramenta de diagnóstico, aqui apresentada oferece aos utilizadores um caminho metodológico 
flexível e eficiente para iniciar a compreender um conjunto de transformações que, como já apontado antes, tem acontecido de forma acelerada dentro dos ecossistemas informacionais nas organizações.

No caso específico utilizado, o SEBRAE-MA, mesmo na fase inicial a ferramenta, já conseguiu apontar questões importantes a serem enfrentadas, tais como a falta de homogeneidade sobre as informações a respeito de regras de utilização dentro da organização, expondo também, potenciais problemas como a utilização fora do horário e um provável excesso de utilização informal pelos colaboradores.

Dentre as sugestões para o caso específico, já pensadas a partir dos dados iniciais do diagnóstico, destacam-se: a elaboração e disseminação de um manual de boas práticas no uso do WA, estabelecendo regras formais para uso e propondo normas de utilização e padronização de publicações institucionais. As respostas também indicam e reforçam a relevância do tema estudado e apontam para a necessidade do produto proposto.

\section{Referências}

ALVES, Paulo. Whatsapp supera facebook e se torna app mais popular do mundo.

Techtudo, 2019. Disponível em http//www.techtudo.com.br/notícias/2019/01/whasapp-supera-facebook-e-e-o aplicativo-mais-popular-do-mundo.ghtml. Acesso em: 29 jan. 2019.

BRASIL.Senado Federal. Mais de $80 \%$ dos brasileiros acreditam que redes sociais influenciam muito a opinião das pessoas. 2019. Disponível em: https://www12.senado.leg.br/institucional/datasenado/publicacaodatasenado?id =mais-de 80-dos-brasileiros-acreditam-que-redes-sociais-influenciam-muito-aopiniao-das-pessoas, no final de 2019. Acesso em: 22 ago.2020.

BRUM, Analisa de Medeiros. Endomarketing estratégico: como transformar líderes em comunicadores e empregados em seguidores. São Paulo: Integrare, 2017.

\section{CALLON, Michel. Por uma nova abordagem da ciência, da inovação e do mercado: o} papel das redes sociotécnicas. In: PARENTE, André. Tramas da rede: novas dimensões filosóficas, estéticas e políticas da comunicação. Porto Alegre: Sulina, 2010 . 
CORRÊA, Elizabeth Saad. A comunicação na sociedade digitalizada: desafios para as organizações contemporâneas. In: KUNSCH, MargaridaM. Krohling (org). Comunicação organizacional: aportes conceituais e aplicados. São Paulo: Summus, 2016. v.

GABRIEL, Martha. Marketing na era digital: conceitos, plataformas e estratégias. São Paulo: Novatec, 2010.

HELENA, Denise. Como funciona whatsapp, o famoso sistema de mensagem instantânea. 2013. Disponível em: https://br.wwwhatsnew.com/2013/07/comofunciona-whatsapp-o-famoso-sistema-de-mensagem-instantanea/. Acesso em: 21 ago.2020.

KUNSCH, Margarida Maria Krohling. Planejamento de relações públicas na comunicação integrada. 6.ed.rev., São Paulo: Summus, 2016.

MARCHIORI, Marlene. Faces da cultura e da comunicação organizacional. 2.ed. São Caetano do Sul, SP: Difusão Editora, 2008.

\section{SERVIÇO BRASILEIRO DE APOIO ÀS MICRO E PEQUENAS EMPRESAS. O que é Whatsapp}

Business? Veja dicas para o app comercial de mensagens.2019. Disponível em: https://www.techtudo.com.br/listas/2019/11/o-que-e-whatsapp-business-vejadicas-para-o-app-comercial-de-mensagens.ghtml. Acesso em: 22 ago. 2020.

SCROFERNEKER, Cleusa Maria Andrade (Org.). O diálogo possível: comunicação organizacional e paradigma da complexidade. Porto Alegre: EDIPUCRS, 2008.

\begin{abstract}
:
A work is presented, still in progress, whose objective is to develop a diagnostic tool for the use of WhatsApp in organizational environments. The project, oriented to face real situations, characterizes the initiative as an applied research. The solution involves a data collection instrument, a categorization of the forms of use and an algorithm for basic exploratory analysis of conversations in groups, identified among employees.
\end{abstract}

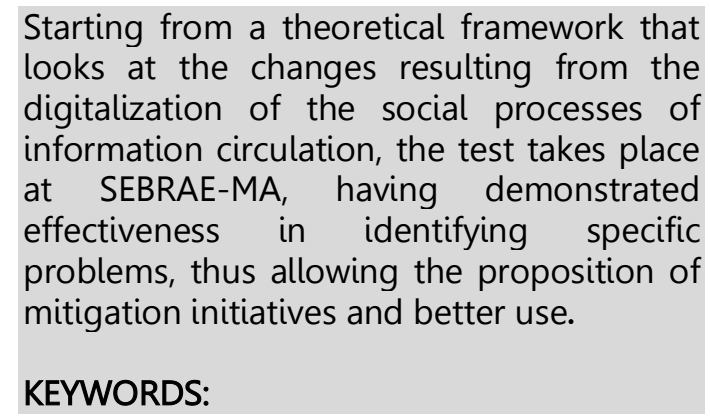

Starting from a theoretical framework that looks at the changes resulting from the digitalization of the social processes of information circulation, the test takes place SEBRAE-MA having demonstrated problems, thus allowing the proposition of KEYWORDS: 
Organizational communication; Contemporaneity; Digital information communication technologies.

\section{RESUMEN:}

Se presenta un recorte de la investigación en progreso, cuyo objetivo es desarrollar una herramienta de diagnóstico del uso de WhatsApp en ambientes organizacionales. El proyecto orientado para el enfrentamiento de situaciones reales caracteriza la iniciativa como investigación aplicada. La solución implica en la recogida de datos, una categorización de las formas de uso y un algoritmo para el análisis exploratorio básico de las conversaciones en grupos, identificados entre los colaboradores. A partir de un referencial teórico que mira a los cambios resultantes de la digitalización de los procesos sociales de circulación de información, la aplicación test ocurre en el SEBRAE-MA y ha demostrado efectividad en la identificación de problemas específicos lo

PALABRAS-CLAVES:

Comunicación organizacional, Contemporaneidad, Tecnologías digitales de información y Comunicación. 